\title{
Formación en valores: iresponsabilidad de la Facultad de Derecho?
}

\author{
BEATRIZ BOZA DIBÓS* \\ FERNANDO DEL MASTRO PUCCIO**
}

«Nada hay más difícil que realizar, ni de éxito más dudoso, ni más peligroso de manejar que la iniciación de un nuevo orden de cosas. Pues el reformador tiene como enemigos a los que se benefician con el antiguo orden, y solo tibios defensores en quienes se beneficiarían con el nuevo».

Nicolás Maquiavelo ${ }^{1}$

SUMARIO: I. LA RESPONSABILIDAD PROFESIONAL DEL ABOGADO.- 1. LA SINGULARIDAD DE LOS VALORES EN EL EJERCICIO DE LA ABOGACÍA. 2. DESAFÍOS DE LA RESPONSABILIDAD PROFESIONAL DEL ABOGADO. II. TEORÍA SOBRE LA FORMACIÓN EN VALORES.- 1. BREVE INTRODUCCIÓN A LOS VALORES. 2. EL PAPEL DE LA EXPERIENCIA EN LA FORMACIÓN DE LA PERSONALIDAD MORAL. 3. IMPORTANCIA DE LA CURRÍCULA OCULTA. 4. MODELOS TEÓRICOS DE EDUCACIÓN EN VALORES SEGÚN LA DOCTRINA. III. NUESTRA PROPUESTA.- 1. MODELO EDUCATIVO SISTÉMICO. 2. LA FORMACIÓN EN VALORES DEL ESTUDIANTE DE DERECHO. 3. MÉTODOS PARA LA FORMACIÓN EN VALORES EN DERECHO. IV. CONCLUSIÓN.

Valores como la libertad, la amistad, la justicia o el principio de veracidad y el valor de la palabra, ison universales o tienen una concreción específica para el abogado? ¿Tiene cada profesión exigencias éticas

* Beatriz Boza Dibós (bboza@ ciudadanosaldia.org) es profesora de la Facultad de Derecho de la Pontificia Universidad Católica del Perú, donde se desempeña, desde 2003, como coordinadora del curso de Ética y ResponsabilidadProfesionaldel Abogado.Liderólaelaboracióndelosmaterialesdeenseñanzadelcursoy esautoradediversostextosacadémicosqueabordanlosdistintosaspectosdelaresponsabilidadprofesional delabogado. Diseñóy organizatodos los semestres lacontiendadeestudiantes «Abogadosal Banquillo». Desde 2004, lidera un Grupo de Estudios sobre Ética y Responsabilidad Profesional del Abogado, con los mejoresalumnos delcurso, quesereúnecada dossemanas, y coordinadesdelaPUCPlaelaboración deun NuevoCódigodeÉticay ResponsabilidadProfesionaldelAbogado.Desde2005,esmiembrodelaComisión de Plan de Estudios de la Facultad y lidera la Sub Comisión de Ética y Valores para la modificación del Plan de Estudios.

** Fernando Del Mastro Puccio es bachiller en Derecho por la PUCP y profesor adjunto del curso de Ética y ResponsabilidadProfesional.Actualmente,esmiembrodelGrupodeEstudiossobreÉticayResponsabilidad Profesional del Abogado y de la Comisión de Reforma del Plan de Estudios de la Facultad de Derecho de la PUCP, donde se desempeña como secretario técnico de la Sub Comisión de Ética y Valores. Asimismo, se desempeña como colaborador del Global Network for Judicial Iniciatives (GNJI) del Vance Center del Colegio de Abogados de Nueva York. Fue miembro de la Asociación Civil Themis, donde se desempeñó como director de la Comisión de Enfoque (enero de 2005 a julio de 2006) y director fundador de la Comisión de Desarrollo Social (julio 2006 a diciembre 2006), en la que elaboró el proyecto «Defensorías urbanas: una soluciónalaviolenciafamiliar", queactualmenteseestáejecutandoconelfinanciamientodelaFundación Catholic Relief Services (CRS). En el ámbito laboral, ejerce el cargo de asistente en el Instituto de Defensa Legal, donde trabaja temas de reforma judicial y acceso a la justicia. Ha escrito diversos artículos sobre educación legal, ética y acceso a la justicia.

1 El Príncipe. Madrid: Cátedra, 2003, p. 54. 
propias? ¿Se basa el ejercicio de la abogacía en valores que adquieren una concreción distinta a la de otras profesiones? iDe ser ese el caso, dónde y cómo aprende el futuro abogado esos principios y valores? iEs responsabilidad de las facultades de Derecho contribuir a la formación en valores de sus egresados? En un contexto de crecientes exigencias respecto de la eficacia y productividad de los abogados en tanto proveedores de servicios legales, ipor qué sería relevante abordar temas éticos especialmente a nivel de la formación universitaria? ¿El mercado no requiere acaso de egresados que dominen destrezas legales y que cuenten con sólidos conocimientos del Derecho? Estas son algunas de las interrogantes que buscamos dilucidar a continuación.

\section{LA RESPONSABILIDAD PROFESIONAL DEL ABOGADO}

Para comenzar, analizamos si el profesional del Derecho debe actuar en función de valores que tienen connotaciones particulares en la práctica de la profesión legal. Es decir, si más allá de la enunciación abstracta de un valor, estos se concretan en deberes específicos que le exigen al abogado en su quehacer cotidiano el desarrollo de medidas concretas, enfocadas en las particularidades del ejercicio de la profesión legal.

\section{La singularidad de los valores en el ejercicio de la abogacía}

En principio, un profesional puede asumir cualquier encargo en la medida que tenga la competencia profesional y el tiempo necesario para llevarlo a cabo. Así, en principio, un ingeniero, médico o arquitecto es libre de recibir a cualquier cliente, mientras que un abogado no. El abogado deberá cuidar, por ejemplo, no tener conflictos de interés respecto del asunto. Asimismo, el ingeniero, médico o arquitecto puede, en ciertos casos, desempeñar sus funciones sin necesidad de conocer exactamente quién es el cliente y si este es quien paga sus honorarios; es más, al médico solo le basta tener al ser humano frente suyo para tratarlo. En el caso del abogado, este sí tiene que identificar al cliente pues es solo a él/ella a quien le debe lealtad y secreto profesional y cuyo interés debe patrocinar celosamente — con independencia de quién paga por sus servicios-.

La amistad como un valor tiene consecuencias distintas para el abogado frente a ingenieros, médicos y arquitectos, por ejemplo. El hecho que el ingeniero, médico o arquitecto sea amigo o hermano del propietario con quien está negociando la compra del terreno, del vecino con quien tiene un desacuerdo o del trabajador que demanda beneficios sociales no afecta su relación ni desempeño profesional como ingeniero, médico o arquitecto, cosa que sí ocurre en el caso del abogado. La importancia de cómo el profesional del Derecho se vincula con este valor adquiere 
connotaciones específicas en nuestra sociedad tan caracterizada por el «amiguismo», entendido como la priorización del amigo, incluso en perjuicio de valores como la justicia o la igualdad. ${ }^{2}$

La justicia es un valor que en el marco de la formación del estudiante de Derecho adquiere contenidos específicos que pueden negar incluso la verdad convencional sobre culpabilidad e inocencia, justicia e injusticia, etcétera. Así, a modo de ejemplo, ante una agresión flagrante y confesión de parte, cualquiera podría concluir que la persona es culpable y merece sanción; el abogado, en cambio, sabe que incluso el confeso tiene derecho a ser defendido y que si acepta el patrocinio podrá buscar demostrar condiciones que mitiguen la responsabilidad del acusado, así como garantizar que se cumpla con un debido proceso.

Por otro lado, existen situaciones en las que de acuerdo con un sentido común de justicia, el resultado debería ser uno distinto al que establece el Derecho. Cuando un caso en el Poder Judicial se resuelve en la última instancia y la sentencia queda consentida, ya no existe posibilidad de cuestionar lo que ha sido decidido, por más «injusto» o «corrupto» que hubiese sido el proceso. Aun si surgen nuevas pruebas o si la decisión para la mayoría es claramente injusta, en principio, esa sentencia no puede ser modificada por tener carácter de cosa juzgada.

Otro ejemplo de la singularidad de los valores en el ejercicio de la abogacía lo tenemos en la adquisición de bienes muebles de buena fe, de acuerdo con la cual un ladrón podría robar un reloj y vendérselo a otra persona que no sabe que es robado. Por más que el propietario a quien le robaron el reloj pueda identificarlo, la persona que lo adquiere de buena fe es la nueva propietaria y no hay nada que pueda hacerse para recuperar el reloj. Un ejemplo más podría ser el de la justicia por mano propia ante la flagrancia de un delito grave, ya que, por más «justo» que sea el resultado, el abogado sabe que no es justicia en tanto se debe respetar el ordenamiento jurídico.

En estos casos, el Derecho exige que las reglas y principios propios del sistema legal se mantengan porque de esa manera se preserva la seguridad jurídica. A diferencia de un médico, arquitecto o ingeniero, un profesional del Derecho debe tener el bagaje conceptual y la convicción que le permitan comprender la racionalidad de estas reglas, respetarlas y, en su caso, poder explicarlas y defenderlas ante su cliente y la sociedad.

Asimismo, a diferencia del abogado, usualmente la atención del ingeniero, médico o arquitecto gira en torno a lo que quiere su cliente, a quienes ellos se deben, mientras que el abogado también tiene deberes respecto de la autoridad, a quien se debe el letrado. El respeto al colega adquiere en el campo del ejercicio del Derecho connotaciones muy diferentes a

FORMACIÓN EN VALORES: ¿RESPONSABILIDAD DE LA FACULTAD DE DERECHO? 
las que suele observar el ingeniero, médico o arquitecto, toda vez que es función del colega en juicio, por ejemplo, defender la posición adversa con convicción e incluso pasión. Otro ejemplo más: el ingeniero, médico o arquitecto puede hablar ante la opinión pública como experto sobre los temas de su competencia, por lo general, sin necesidad de identificar a su cliente -incluso en algunos casos el médico debe omitir la identidad de su cliente para proteger su intimidad - El abogado, sin embargo, no debe presentarse como experto desinteresado ante la opinión pública para comentar sobre un caso si está patrocinando a un cliente en ese asunto.

Finalmente, el valor de la palabra adquiere para el abogado una dimensión propia frente a otras profesiones. En efecto, aun cuando un ingeniero o un médico deben cumplir con su palabra y, por ejemplo, entregar una obra a tiempo o realizar una consulta en el día pactado, el abogado tiene por función interpretar, documentar y custodiar el cumplimiento de la palabra empeñada, siendo su ejercicio profesional medular para el principio de pacta sunt servanda, que supone que lo pactado es obligatorio. Así, el valor de la palabra adquiere connotaciones específicas en el ejercicio de la profesión legal.

La puntualidad es un valor social que debe inspirar la conducta de todo ciudadano como muestra de respeto al otro; en el caso de la abogacía, adquiere una connotación mayor, vinculada al valor de la diligencia. A diferencia de otras profesiones, el incumplimiento de un plazo puede acarrear consecuencias nefastas para el cliente y para la confianza que la ciudadanía tenga en el sistema legal.

Los valores de justicia y solidaridad tienen también otras concreciones que, aunque no son exigibles, pueden ser evaluadas y asumidas en distintos niveles por los abogados. Así, el compromiso con la justicia puede llevar a un abogado a asumir retos muy concretos, como dedicarse a la función jurisdiccional o, desde la práctica privada, el valor de la solidaridad se puede concretar en asumir casos pro bono.

Estas reglas «propias del ejercicio de la abogacía» que hemos revisado, esto es, aquellas que parten de la concreción de los valores en la profesión legal, constituyen la responsabilidad profesional del abogado y son, por ende, de cumplimiento obligatorio en su ejercicio. Así, aun cuando un abogado es absolutamente libre de elegir a qué dedicarse desde el Derecho, se espera que su comportamiento se adecue a los estándares de responsabilidad establecidos en la profesión. Cualquiera que fuera el área o la forma en que decida ejercer la profesión, un abogado debe comportarse con responsabilidad profesional.

La formación en valores del abogado pasa por que el estudiante pueda comprender e interiorizar cómo el compromiso con el Estado constitucional de derecho impacta en el quehacer cotidiano del profesional en Derecho, particularmente en los principios y valores que inspiran y sustentan la profesión que ha elegido como carrera. El estudiante de 
Derecho, en tanto futuro abogado, debe aprender y conocer a fondo los valores de la profesión — cuáles son, qué alcance tienen-, pues estos son consustanciales al ejercicio del Derecho.

\section{Desafíos de la responsabilidad profesional del abogado}

El estudiante de Derecho enfrenta un desafío grande, toda vez que el abogado es parte esencial de la defensa del orden democrático a través de su participación en el sistema jurídico del país. Por eso, debe respetar la función de la autoridad y ejercer el Derecho, cualquiera fuere el ámbito en que se desempeñe, con sujeción a los principios de lealtad, buena fe, probidad, veracidad y honradez. El objeto principal del quehacer del abogado no se limita a defender diligentemente los intereses de su empleador o cliente, sino que tiene por fin la defensa de los derechos de las personas y la consolidación del Estado Constitucional de Derecho, la justicia y el orden social. La probidad e integridad de la conducta del abogado, cualquiera fuere el ámbito en el que se desempeñe, es esencial para el adecuado funcionamiento del sistema de justicia, la vigencia del Estado Constitucional de Derecho y la vida en sociedad. ${ }^{3}$

El abogado, por el solo hecho de serlo, debe comportarse de manera que inspire confianza. Al servir a su cliente debe actuar con competencia y diligencia y está obligado a cumplir con los deberes de información, confidencialidad, lealtad, celo en el patrocinio, cuidadoso manejo de los bienes del cliente, todo esto en el marco de la ley y del Estado Constitucional de Derecho. Todo lo anterior se materializa en derechos y deberes concretos y exigibles por la sociedad que se despliegan en el ámbito de la responsabilidad profesional.

La realidad nacional, a su vez, exige que las facultades de Derecho realicen acciones concretas para promover la responsabilidad profesional. En efecto, la corrupción, los escándalos por faltas éticas de los abogados y la gran desconfianza de la sociedad en estos dan cuenta de un contexto que requiere de un compromiso a nivel de la educación universitaria.

Según una encuesta publicada el 23 de noviembre de 2008 en El Comercio, uno de los principales problemas del país es la corrupción y la falta de cumplimiento de la ley por parte de los ciudadanos y autoridades. Lamentablemente, los profesionales del Derecho no escapamos a esta realidad. De alguna manera, el actual desprestigio de la profesión legal parte justamente del vínculo que tiene con la corrupción, la falta de cumplimiento de estándares éticos y la falta de compromiso con valores como la justicia o la solidaridad. No debe sorprender, entonces, que las personas confíen más en la palabra de bomberos (93\%), profesores (82\%), médicos (80\%), psicólogos (78\%), enfermeras (72\%),

FORMACIÓN EN VALORES: ¿RESPONSABILIDAD DE LA FACULTAD DE DERECHO? 
ingenieros (67\%), periodistas (49\%), empresarios (40\%), la gente en general $(38 \%)$ y policías (26\%) antes que en la palabra de un abogado $(21 \%){ }^{4}$

Lejos de ser una mera estadística, estas cifras representan problemas cotidianos que sufren los ciudadanos y el país, como demoras en los procesos, abogados que engañan a sus clientes, que lucran indebidamente, que no informan, que incurren en actos de corrupción, que no actúan con solidaridad, entre otros.

Este problema tiene, en nuestro medio, diversas causas, entre otras: (i) aspectos culturales vinculados con la educación; (ii) falta de un diseño normativo moderno y consensuado entre los operadores jurídicos que genere institucionalidad; y (iii) bajo nivel de conocimiento por parte de los operadores jurídicos, de las reglas y mecanismos necesarios para abordar problemas éticos y desarrollar prácticas de responsabilidad social. Teniendo en cuenta esta diversidad de causas y convencidos de la bondad de adoptar un régimen de responsabilidad profesional, desde la Facultad de Derecho se han venido impulsando esfuerzos orientados a la elaboración consensuada de un Código de Responsabilidad Profesional del Abogado. Ello en razón de que, a través de una normativa moderna, no solo se busca atacar la segunda causa mencionada - ausencia de un sistema normativo adecuado-, sino que también se pretende ayudar a mejorar, a través de su creación consensuada y aplicación guiada, el conocimiento por los abogados, en tanto operadores jurídicos, de las reglas y mecanismos que dicha normativa contiene. A su vez, una nueva normativa acorde con los tiempos actuales puede facilitar y enriquecer la enseñanza de estas materias.

¿Cuál es el papel que, frente a esa realidad, desempeñan las facultades de Derecho? ¿Deben formar a sus estudiantes en valores o limitarse a brindarles conocimientos y destrezas? iImporta solo que el alumno sepa «hacer»y «saber hacer» o las facultades de Derecho tienen responsabilidad de trabajar en torno al «ser» del futuro profesional del Derecho? ¿Se debe enseñar al alumno a usar el Derecho como una herramienta para cualquier fin?

Lo desarrollado hasta este punto nos genera otro conjunto de dudas de central importancia. Sabemos que la meta es contar con egresados que respeten los estándares profesionales, pero icómo abordarlos? ¿Cómo enseñar de modo adecuado y con resultados estos valores aplicados a la profesión? ¿De qué modo formar profesionales con estándares éticos? ¿Basta con buenas intenciones o estamos ante la necesidad de realizar diversas acciones que permitan alcanzar los objetivos?

Estas preguntas nos llevan a un segundo punto de reflexión. Reconociendo que no somos especialistas en educación o psicología, debemos analizar las diversas teorías que se han desarrollado respecto 
a la educación moral y a los mecanismos y métodos que, de acuerdo con la doctrina especializada, deben usarse para abordar la formación en valores. Este marco permite luego entrar al tema específico de los mecanismos a seguir para educar en valores a los alumnos que están aprendiendo Derecho. En este punto debemos comenzar por reconocer que quien estudia Derecho se forma no solo en las aulas y pasadizos de una facultad, sino también en sus centros de prácticas pre-profesionales, en los estudios generales y en la vida universitaria en general. En cada caso, como exponemos a continuación, hay acciones que adoptar y teorías que seguir.

\section{TEORÍA SOBRE LA FORMACIÓN EN VALORES}

En esta sección reseñamos brevemente en qué consisten los valores, para luego pasar a describir la importancia que tienen la experiencia y la currícula en la formación moral, y posteriormente abordamos los diferentes modelos de educación moral que han sido desarrollados en la doctrina.

\section{Breve introducción a los valores}

Un valor es «[...] algo apreciado como bueno, valioso o deseable». ${ }^{5}$ De allí que los valores estén relacionados con «[...] inspiraciones de los juicios y de las conductas $[\ldots] » .6$ En ese sentido, han sido caracterizados como «guías estructurales u orientaciones», en tanto están «relacionados con los intereses y propósitos particulares de los seres humanos». ${ }^{7}$ Por ello, se ha afirmado que una forma de definirlos «[...] es verlos como intrínsecos a todas nuestras acciones y decisiones» ${ }^{8}$, en tanto justamente tienen como una característica central el que «[...] se expresan mediante actos concretos». ${ }^{9}$

De estas aproximaciones podemos desprender que los valores son aquellas motivaciones que llevan al ser humano a comportarse o a pensar de un determinado modo, en tanto se encuentran en la base de las acciones humanas al ser su sustento y origen. ${ }^{10}$

5 SchmidT, Eduardo. Op. cit., p. 65.

6 Capella Riera, Jorge. «Una posición en la educación en valores». Revista Educación, vol. VII, n 13, Lima, 1998, p. 7.

7 HallidAY, John. «Values and Further Education». British Journal of Education Studies, vol. 44, n 1, 1996, p. 75 (traducción libre).

8 DunCAN, Dianey MeterSıLcock. «Values Acquisition and Values Education: Some Proposals». British Journal of Education Studies, vol. 49, n 3, 2001, p. 243 (traducción libre).

9 Schmidt, Eduardo. Op. cit., p. 89.

10 Enunaformaciónenvalores,sonprecisamentelosvaloreslosquedebenserelobjetodetrabajouniversitario, demodoquelasmedidasaadoptargirenentornoalvalormismoynoselimitena suenunciacióny discurso. En ese sentido, la doctrina indica que es importante tener presente que: (i) El profesar una determinada posición respectoaunvalornosignificaquelapersonaquelaprofesaactúaconformeadichovalor. Así, por ejemplo, «laspersonas pueden profesarpúblicamentepuntos devistaencontradelracismo[...] adoptando actitudes racistas en su vida". Véase $i b i d .$, p.244. La formación en valores suponetrascender del discursoa la acción y proveer en la práctica de un entorno que refleje y viva los valores que se profesan. (ii) Unamisma conducta puede ser motivada por diversos valores. Así, por ejemplo, «[...] la conducta valiente puede ser motivada por la ambición, de tal manera que la persona arriesgará su vida en ciertas situaciones a fin de satisfacersunecesidaddeseradmirada»opuede, porejemplo, «serdeterminadaporunagenuinadevoción

FORMACIÓN EN VALORES: ¿RESPONSABILIDAD DE LA FACULTAD DE DERECHO? 


\section{El papel de la experiencia en la formación de la perso- nalidad moral}

La doctrina analizada sobre la formación en valores es unánime al señalar la importancia de la experiencia concreta del alumno y de la cultura del ambiente universitario en tanto organización educativa. Así, el compromiso de un joven con determinados valores responde no solo a una reflexión racional, sino en gran medida también emocional. Este se consigue promoviendo la vivencia de experiencias. Los valores se viven, se experimentan, se sienten y así se interiorizan. Una adecuada formación universitaria debe poder brindar experiencias de diversa índole que el alumno pueda confrontar con sus experiencias previas, reflexionar y, sobre la base de ello, formar su propia opinión y actitud.

Como veremos más adelante, los educadores deben brindar espacios en los que la cultura experiencial, esto es, las prácticas y experiencias con las que llega un alumno a la universidad, puedan ser contrastadas con nuevas experiencias, de modo que exista la posibilidad de reevaluación y complementariedad. El peso de la experiencia influye, entonces, tanto en la formación de los valores como en su cambio o reforzamiento, de modo tal que sin un planteamiento que contemple a la experiencia como factor central en la educación moral, será muy difícil lograr cambios.

Evidentemente, como en el caso de la teoría y las destrezas, el trabajo de experiencias supone también que el profesor y el entorno universitario promueva la reflexión expresa respecto a los valores que se experimentan, de modo que dicho debate complemente debidamente la experiencia y signifique que los alumnos realmente se cuestionen sobre las situaciones vividas en ella. En definitiva, diversos autores ${ }^{11}$ han reconocido que el aprendizaje mediante la experiencia no consiste meramente en permitir que los alumnos tengan experiencias, sino en hacerlos concientes de ellas. Así, por ejemplo, se ha señalado que en la reflexión desde las experiencias «[...] el profesor ayuda a los alumnos a que cobren conciencia de sus propios procesos cognitivos y de los procesos de los demás, así como de la utilización de éstos para resolver problemas y situaciones de la vida $[\ldots] » .{ }^{12}$ De esa forma se asegura que la experiencia sea aprovechada por todos, ya que sin la asistencia de un promotor de reflexión es posible que muchos alumnos se resistan a vivir la experiencia, anulen

a una idea o un fin, por los cuales la personaactúa».Fromm, Erich. Éticaypsicoanálisis. MéxicoD.F: Fondo de Cultura Económica, 2006, p. 68. En el último caso, a su vez, la idea o fin podría ser el amor-a un ser querido o a la patria, por ejemplo-, el altruismo —en tanto la acción valiente permite que determinadas personas mejorensusituación-,entreotros.Entenderladimensiónmúltipledelaccionarhumanoesnecesariopara poderbuscarlacoherenciadelmismo.¿Porquésonimportanteslas reflexionesrecién planteadas? Porque precisamente el hecho de que los valores deben ser el objeto del contenido de la formación del estudiante de Derecho supone no centrar el enfoque, esto es, las propuestas y mecanismos de evaluación, en que los alumnosrealicendeterminadasactividadesomantenganyconozcandeterminadosdiscursos,sinomásbien que interioricen como propios determinados valores.

11 Entre otros, aquellos que venimos siguiendo, como Schmidt, que plantea la necesidad de reflexionar en tornoalavivenciasimuladadecasos, oPuig, queseñalalanecesidad deque las experiencias moralessean guiadas por un "guía experto".

12 Boisvert, Jacques. La formación del pensamiento crítico. México D.F.: Fondo de Cultura Económica, 2004, p. 74. 
inconscientemente los temas conflictivos vividos, no identifiquen cómo la experiencia ha sido vivida por otros o simplemente no puedan identificar problemas vinculados con los valores.

\section{Importancia de la currícula oculta}

Existe un factor de particular relevancia que debe ser trabajado a nivel universitario, pues se trata, según muchos autores, de un aspecto medular en la formación en valores que debemos abordar. Este elemento es el de la currícula oculta. ${ }^{13}$

Nos referimos a la actitud de los profesores y de la institución misma, así como a las relaciones entre ambos y los alumnos, pues estas relaciones tienen consecuencias muy importantes en las actitudes y valores que estos últimos incorporan en su vida. Estas relaciones y los valores que de ellas o de la actuación de los actores se derivan, sin duda ejercen una influencia muy importante en la construcción de la personalidad moral de los alumnos. Estas influencias se dan no tanto en el orden racional como en el emocional.

De hecho, se ha afirmado que: «En el área de las emociones y actitudes que controlan las decisiones éticas, aun más que en el contenido intelectual del currículum de las facultades de Derecho, los estudiantes absorben de diferentes y complejas maneras. Ellos captan las actitudes que los marcan como abogados de sus compañeros y profesores, así como de la discusión dentro y fuera de la clase». ${ }^{14}$

En el caso de la influencia de los profesores, se ha llegado a afirmar incluso que:

[...] la educación humanista no depende de los contenidos de las asignaturas, sino de la relación profesor-alumno, independientemente de los temas que se traten. Una relación humana plena, con tolerancia, comprensión, calidez, deja enormes huellas en la vida del alumno [...]. De modo que el sentido humanista está más ligado a la dinámica del mensaje como vínculo que como contenido. ${ }^{15}$

La influencia, sin embargo, no se limita a las interrelaciones y actitudes de compañeros y profesores. Y es que

[...] la escuela, como cualquier otra institución, desarrolla y reproduce su propia cultura específica. Entiendo por tal el conjunto de significados y comportamientos que genera la escuela como

13 Lacurrículaoculta «[...]hacereferenciaalosmensajesqueprovienendelaculturaescolarydelasrelaciones institucionales e interpersonales cotidianas entre todos sus actores, incluyendo las que la institución educativa establece con la comunidad». Instituto Interamericano de Derechos Humanos. Propuesta curricular y metodológica para la incorporación de la educación en derechos humanos en la educación formal. San José: IIDH, 2006, p. 21.

14 Weinstein B., Jack. «On the Teaching of Legal Ethics». Columbia Law Review, vol. 72, no 3, 1972 , p. 456 (traducción libre).

15 Trahtemberg, León. «Una nueva mirada al vínculo maestro-alumno». En Psicoanálisis y educación. Lima: Sociedad Peruana de Psicoanálisis, 2002, p. 33.

FORMACIÓN EN VALORES: ¿RESPONSABILIDAD DE LA FACULTAD DE DERECHO? 
institución social. Las tradiciones, costumbres, rutinas, rituales e inercias que estimula y se esfuerza en conservar y reproducir la escuela condicionan claramente el tipo de vida que en ella se desarrolla, y refuerza la vigencia de valores, expectativas y creencias ligadas a la vida social de los grupos que constituyen la institución escolar. ${ }^{16}$

La currícula oculta determina las actitudes y valores de los estudiantes. Así, por ejemplo, si tanto los profesores como la institución no son diligentes en el cumplimiento de sus deberes, es muy probable que dicha negligencia se imprima en la conciencia de los alumnos como reflejo del ejemplo de las figuras del profesor o de la institución como tal.

De igual modo, si el profesor es categórico y no plantea dudas, no promueve la reflexión, no promueve el debate y no escucha todas las opiniones dándoles importancia, lo que ocurre es que no solo no existe un debido desarrollo de la reflexión, sino que el valor que se promueve es la sumisión. Ello en razón de que lo que se aprende es a recibir información y a asimilarla irreflexivamente. ${ }^{17}$

Es preciso advertir que la currícula oculta, en el caso de las facultades de Derecho, incluye a otro actor de gran relevancia: los empleadores o maestros de prácticas. ${ }^{18}$ Así como las facultades de Derecho, los centros laborales tienen su propia cultura que influencia también a sus miembros. Esta afirmación adquiere aun más sustento si tenemos en cuenta que los alumnos son practicantes que generalmente buscan ser contratados, por lo que no solo existe un proceso de influencia inconsciente, sino que es muy probable que el alumno, de modo consciente, busque amoldarse a los valores del centro laboral. Esto exige, por ende, incluir a los centros laborales como parte de la currícula oculta de las facultades de Derecho.

A pesar de que no existen estudios que determinen el peso exacto que tiene la currícula oculta en la formación moral de los alumnos de Derecho, lo cierto es que los autores citados coinciden en que la cultura organizacional, esto es, las actuaciones de los profesores, jefes de práctica, personal administrativo y de la institución universitaria en general y, de los empleadores y compañeros de prácticas pre-profesionales, tiene una participación muy significativa en la formación moral, ya que se traduce en ejemplos de quienes tienen una influencia determinante en los alumnos. En el caso de los estudiantes de Derecho, la incidencia de la currícula oculta se magnifica toda vez que en la actualidad la formación práctica y concreta la obtiene el estudiante mediante sus practicas

16 Pérez Gómez, Ángel. La cultura escolar en la sociedad neoliberal. Madrid: Morata, 2004, p. 127.

17 En el ámbito escolar se ha dicho, por ejemplo, que «[...] explícitamente lo que se enseña son matemáticas, física, ciencias naturales, nociones sociales, lenguaje, etc., pero, en definitiva, lo que se está enseñando,y lo que se registra de forma más indeleble, es que la actividad escolar consisteen aprender lo que otro sabe, de la misma manera que lo sabe, y sin necesidad de pensar sobre ello [...]". DeLvaL, Juan. Los fines de la educación. Madrid: Editora Siglo XXI, 1991, p. 31.

$18 \mathrm{Y}$ es que, aun cuando no existe en el Perú ningún estudio que determine el peso que las costumbres o requerimientosdelosempleadoresejerceenlosestudiantesdeDerecho,lociertoesquelasconsideraciones anteriores se aplican a las prácticas pre-profesionales. 
pre-profesionales en alguna entidad estatal, estudio jurídico o empresa, esto es, fuera del entorno universitario y sin ninguna supervisión o retroalimentación práctica por parte de la universidad.

Dejando sentada la importancia de la experiencia y la currícula oculta para el aprendizaje moral del joven, existen diversos enfoques de cómo y bajo qué principios organizar dicha formación. A continuación se presentan, desde un análisis teórico doctrinario, cuáles son los modelos educativos para lograr una sólida formación en valores.

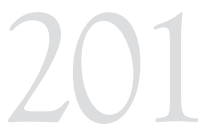

FORMACIÓN EN VALORES: ¿RESPONSABILIDAD DE LA FACULTAD DE DERECHO?

\section{Modelos teóricos de educación en valores según la doctrina}

En términos generales, podemos agrupar los distintos enfoques educativos en torno a los siguientes tres modelos de educación moral: (i) el modelo de educación por socialización; (ii) el modelo de educación por clarificación de valores; y (iii) el modelo de educación por construcción de la personalidad moral. ${ }^{19}$

\section{a. Socialización}

La educación de valores por socialización se basa en la incorporación, por parte de la unidad educativa, del conjunto de valores que imperan en la sociedad. Desde esta perspectiva, el proceso de aprendizaje y la labor del educador puede ser asimilada a la incorporación de un aspirante a una asociación. Así, se señala que:

La socialización moral puede compararse con la entrada de un nuevo miembro a una entidad que tiene historia y se rige por reglas. En estos casos la formación puede entenderse como una minuciosa visita durante la cual el aspirante observa el funcionamiento de la asociación y recibe las explicaciones pertinentes de uno de sus miembros calificados. Tras la visita se supone que el aspirante ya conoce, acepta y es capaz de practicar todas las normas que pautan el funcionamiento de la institución [...]. Esta concepción otorga al educando el papel de aspirante, que observa, pregunta y asimila. ${ }^{20}$

19 Auncuandoexistenposturassegúnlascualeslaeducacióndevaloresolaeducaciónmoral, particularmente en el ámbito universitario, carece de fundamento en tanto es imposible que las personas varíen aquellos valoresinculcadosensuprimerainfanciao,incluso, determinadosgenéticamente,consideramosque, desde nuestro punto de vista, se trata de posturas deterministas que no compartimos. Véase sobre el particular: Damon, William, Jenni Menony Kendall Cotton. «The Development of Purpose During Adolescense». Applied Developmental Science, vol. 7, n 3, Stanford University, 2003.

20 «Losautoresquedeun modou otropueden vincularsealasposicionessociologistas [sic]entiendenquela educación moral debe insertar o ajustar a los individuos en la colectividad a la cual pertenecen. Describen la formación moral como un proceso mediante el cual los sujetos reciben de la sociedad el sistema vigente devaloraciones y normas. Valoraciones y normas que se les imponen con una fuerza ajena su conciencia y a su voluntad. Se les imponen con la autoridad que emana de una entidad social superior a los individuos [...] sin que su conciencia y voluntad tengan papel alguno en la aceptación, rechazo o modificación de las prescripciones morales que recibe». Puig R., Josep Maria. La construcción de la personalidad moral. Barcelona: Paidós, 1996, pp. 20 y 241. 


\section{b. Clarificación de valores}

La educación por clarificación de valores parte del relativismo: no hay valores mejores ni peores. A esta premisa se suman, en este modelo, una confianza casi absoluta en la capacidad del ser humano para decidir respecto de los valores a adoptar y, consecuentemente, una participación casi nula de los educadores.

Como advierte Puig: «Cuando los modelos educativos basados en valores absolutos entran en crisis, suelen imponerse posturas que de una forma u otra apelan a una idea de educación moral basada en una concepción relativista de los valores. Estos modelos suponen que los conflictos de valor sólo pueden solucionarse apelando a algún tipo de decisión subjetiva del individuo implicado en ellos». De ese modo, el método en cuestión supone que las cuestiones morales «[...] deben resolverse mediante decisiones subjetivas, más o menos ilustradas, de los individuos afectados». ${ }^{21}$

\section{c. Construcción de la personalidad}

El modelo de la educación como un elemento para la construcción de la personalidad moral «[...] parte, en tanto que primer principio, de la convicción de que la moral no es algo dado de antemano, presupuesto, o que simplemente se decide o elige, sino que la moral debe hacerse mediante un esfuerzo complejo de elaboración o reelaboración de las formas de vida y de los valores que se consideran correctos y adecuados para cada situación».22

Esta postura, sin duda, se ubica en el ámbito del constructivismo. De acuerdo con esta corriente, aplicada al ámbito de la educación, el alumno que llega a la escuela o a la universidad «[...] trae consigo una historia repleta de experiencias y modos de comprensión específicos, así como presupuestos que determinan su conocimiento y actuación». ${ }^{23}$ Sin embargo, reconoce a su vez que dichos condicionamientos y experiencias no son determinantes y, con diversos mecanismos, pueden ser reevaluados por el alumno y, de ser el caso, incluso modificados. Claro

21 PuIGR.,JosepMaria.Op.cit.,p.31.Siguiendolalíneadeldesarrolloefectuadoenelmodeloanterior, lapráctica educativa, en la clarificación de valores, puede ser asociada a la arqueología. Así, se ha explicado que: «La educaciónmoralcomoclarificacióndevalorespodríaexplicarelprocesoformativousandometáforaspropias de las investigaciones arqueológicas [...]. Laeducación moraltendríabastante deexcavaciónen buscade algún objeto cuya existencia se supone y al cual damos una gran importancia [...]. En esta concepción moral el educando tiene un papel privilegiado: es el investigador que conduce activamente las pesquisas. En cambio, el educador queda relegado a un plano secundario: o bien, en la mejor de las hipótesis, puede inspirar la búsqueda con alguna indicación acertada [...]; o bien, selimitaráa colaboraren tareas logísticas totalmente accesorias". Ibid., p. 242.

22 Ibid., p. 66. Partimos, entonces, de una postura «[...] socioconstructivista, que defiende el proceso de desarrollodelapersonacomounauténticoprocesodeconstrucción personal,graciasalaparticipaciónen prácticasformativasysociales. Estaperspectivapretendesuperarlosdosextremos paradigmáticosquese han dadoenel tratamiento de la formación moral de la persona. Por un lado,elmás vinculadoa laformación moralcomoun procesodeinculcación devalores, dondelapersonahadereproducirlosqueseletransmiten e incorporarlos a sus actuaciones sociales y a sus patrones de pensamiento personales. Por otro lado, el más vinculadoal relativismoy/o subjetivismo radical. El primer extremo muestra una falta de confianzaen el proceso de construcción personal, y, porende, en la autonomíay responsabilidad dela propia persona». MARÍN MARTínEz, Miquely otros. «Launiversidad comoespaciodeaprendizajeético». Revista lberoamericana de Educación, no 22, agosto de 2002, p. 13.

23 Pérez Gómez, Ángel. Op. cit., p. 243. 
está que el peso de la experiencia previa no puede ser subestimado, por lo que las medidas para fomentar la reevaluación deben tener un sólido sustento.

A fin de determinar cuáles son dichas medidas en el modelo de la construcción de la personalidad moral, requeriremos, como en los casos anteriores, de la utilización de una metáfora. En este caso, se trata de compararla con el trabajo dentro de un taller:

Comparar la educación moral con la actividad que se lleva a cabo en un taller significa entender que la formación es el resultado de la relación que establece un aprendiz con el oficial experto que le tutoriza a propósito de las tareas propias del oficio. Es un trabajo de iniciación activa a un saber que el aprendiz irá haciendo suyo progresivamente. Aunque durante dicho proceso de apropiación de conocimientos quizás pueda llegar a modificarlos y mejorarlos. ${ }^{24}$

De alguna manera, el principal sustento de esta postura gira en torno a poder brindar experiencias de diversa índole que se confronten con las experiencias previas del alumno.

Cada uno de los modelos educativos analizados tiene bondades y desventajas. Desde nuestro punto de vista, el modelo que deben adoptar las facultades de Derecho es el de socialización. Como veremos, la finalidad es que toda la entidad esté comprometida con el cumplimiento de estándares obligatorios y que el alumno, de ese modo, ingrese a una organización donde los comprende y aprende a cumplir. Ello sin perjuicio de que los otros dos modelos puedan presentar beneficios en diferentes ámbitos donde los estudiantes establecen vínculos y que incluso sean muy útiles para definir algunos mecanismos para trabajar en torno a la responsabilidad profesional.

\section{NUESTRA PROPUESTA}

Habiendo presentado desde una perspectiva teórico-doctrinaria los tres modelos educativos para lograr una sólida formación en valores, toca preguntarse cuál es el enfoque más apropiado para la formación que imparte una facultad de Derecho y qué herramientas metodológicas o rubros de aprendizaje moral deben desplegarse. Nuestro enfoque parte de entender que el alumno no se forma únicamente en la Facultad de Derecho, aunque esta es el ámbito fundamental en su formación. Por ello, luego de presentar un modelo sistémico, nos centraremos en propuestas que podrían adoptarse en la Facultad de Derecho.

FORMACIÓN EN VALORES: ¿RESPONSABILIDAD DE LA FACULTAD DE DERECHO? 


\section{Modelo educativo sistémico}

Desde una perspectiva de educación superior universitaria centrada en la libertad de la persona humana, el enfoque de la educación por construcción de la personalidad moral presenta bondades y ventajas a priorizar. No obstante ello, quizás el enfoque más acertado tome en cuenta también aspectos de los otros dos modelos educativos analizados, en el sentido que el estudiante de Derecho pertenece de un lado a una comunidad universitaria, de otro se prepara para ingresar, a través del aprendizaje de un oficio y ética específica, a una profesión, en una etapa de su vida en la que está perfilando en libertad su propia personalidad moral. En ese sentido, proponemos un abordaje sistémico integral para la formación en valores del estudiante de Derecho que prioriza el enfoque de la educación por socialización a nivel de la facultad de Derecho, aunque recoge propuestas y mecanismos de las otras dos teorías de la formación moral.

De alguna manera, cada uno de los vínculos que tiene el estudiante con los distintos estamentos y comunidades de aprendizaje a los que pertenece - por ejemplo, comunidad universitaria, comunidad de la profesión elegida, en este caso Derecho, y su propio sentido de justicia-, podrían estar referidos a distintos modelos educativos, como se grafica en el cuadro que sigue:

Enfoque sistémico para la formación en valores

\begin{tabular}{|c|c|c|c|c|}
\hline $\begin{array}{c}\text { Modelo } \\
\text { educativo }\end{array}$ & $\begin{array}{l}\text { Vínculo del } \\
\text { estudiante }\end{array}$ & $\begin{array}{l}\text { Contenidos de } \\
\text { aprendizaje }\end{array}$ & $\begin{array}{c}\text { Responsables de } \\
\text { proveerlos }\end{array}$ & Valores \\
\hline Clarificación & $\begin{array}{l}\text { Miembro de } \\
\text { la comunidad } \\
\text { universitaria }\end{array}$ & $\begin{array}{l}\text { Valores y estilo de } \\
\text { convivencia que } \\
\text { profesa la PUCP }\end{array}$ & $\begin{array}{l}\text { Estudios Generales } \\
\text { (EEGG) y univer- } \\
\text { sidad }\end{array}$ & $\begin{array}{l}\text { Diversidad, } \\
\text { solidaridad, } \\
\text { responsabilidad y } \\
\text { excelencia }\end{array}$ \\
\hline Socialización & $\begin{array}{l}\text { Miembro de } \\
\text { la Facultad } \\
\text { de Derecho }\end{array}$ & $\begin{array}{l}\text { Aprendizaje del } \\
\text { oficio y valores } \\
\text { propios de la ca- } \\
\text { rrera de Derecho }\end{array}$ & $\begin{array}{l}\text { Facultad y Depar- } \\
\text { tamento de De- } \\
\text { recho }\end{array}$ & $\begin{array}{l}\text { Responsabilidad } \\
\text { profesional, justi- } \\
\text { cia, veracidad, in- } \\
\text { tegridad, libertad, } \\
\text { responsabilidad, } \\
\text { lealtad, diligencia, } \\
\text { transparencia } \\
\text { excelencia }\end{array}$ \\
\hline Clarificación & $\begin{array}{l}\text { Prácticas pre- } \\
\text { profesionales }\end{array}$ & $\begin{array}{l}\text { Aprendizaje de } \\
\text { valores propios de } \\
\text { la carrera desde } \\
\text { un enfoque prác- } \\
\text { tico }\end{array}$ & Jefe de prácticas & $\begin{array}{l}\text { Todos los valores } \\
\text { antes enumerados }\end{array}$ \\
\hline $\begin{array}{l}\text { Construcción } \\
\text { de la persona- } \\
\text { lidad }\end{array}$ & $\begin{array}{l}\text { Profesional } \\
\text { en formación }\end{array}$ & $\begin{array}{l}\text { Personalidad mo- } \\
\text { ral propia }\end{array}$ & $\begin{array}{l}\begin{array}{l}\text { Facultad y De- } \\
\text { partamento de }\end{array} \\
\text { Derecho, EEGG y } \\
\text { universidad }\end{array}$ & $\begin{array}{l}\text { Todos los valores } \\
\text { antes enumerados }\end{array}$ \\
\hline
\end{tabular}

Fuente: Elaboración propia. 
Como podemos notar, el primer vínculo del estudiante lo desarrolla con la comunidad universitaria de Estudios Generales (EEGG). La universidad promueve valores como la diversidad y la solidaridad, y en EEGG intenta acercar al joven a conocer y entender la realidad nacional. En EEGG, en ese sentido, puede brindarse una amplia oferta curricular que incluye cursos que vinculan diversas disciplinas con la realidad nacional. Por lo demás, la diversidad de los estudiantes que ingresan a EEGG suele ser un factor que rompe con los moldes de la educación secundaria y permite un acercamiento a la diversidad nacional. Así, los alumnos tienen en este ámbito la oportunidad de decidir cómo se vinculan con el resto de sus colegas y con el material estudiado. De allí que en este punto el modelo a imperar sea el de la clarificación de valores.

En el ámbito de la Facultad de Derecho el panorama cambia, ya que el alumno se iniciará en el estudio de una profesión. Por ello, lo primero que debe buscar la universidad es inculcar la responsabilidad profesional que materializa los valores de veracidad, integridad, libertad, responsabilidad, lealtad, diligencia, transparencia, justicia y solidaridad. En este punto, a nivel de la Facultad de Derecho, el modelo sería el de educación por socialización sumado a medidas concretas de currícula oculta y algunas propuestas desde el modelo de la construcción de la personalidad, toda vez que el rol es el de enseñar los deberes éticos que caracterizan al profesional del Derecho y ser ejemplo de ello.

Finalmente, durante su paso por una facultad de Derecho, el alumno va tomando decisiones respecto de su grado de compromiso con valores como la justicia, la solidaridad o la diversidad. En este punto es central que la facultad promueva la reflexión en torno a los mismos siguiendo las pautas del desarrollo de la personalidad moral.

A su vez, en el ámbito de las prácticas pre-profesionales el alumno recibe una formación en valores que, aunque no es explícita, contiene valores implícitos que muchas veces son contravalores. En la actualidad, por lo general, las facultades no tienen injerencia directa respecto de qué prácticas sigue el alumno y qué ocurre en estas. No obstante ello, sí puede cumplir un rol clarificador y brindar, en consecuencia, información respecto del contenido de la diversidad de prácticas que existen y de la idoneidad de cada una en temas principalmente vinculados con el cumplimiento de estándares éticos.

Si bien, como se ha señalado, dependiendo del tipo de relación que entabla el estudiante de Derecho, cada uno de los enfoques educativos analizados presenta bondades y desventajas, consideramos que el enfoque más acertado prioriza la educación por construcción de la personalidad moral. Ahora bien, icómo se aplica ello al ámbito de una facultad de Derecho? Esa es la discusión que abordamos en el punto que sigue. 


\section{La formación en valores del estudiante de Derecho}

Debemos comenzar analizando qué supone la formación en valores en el marco de la educación legal, así como indicando qué aspectos son los prioritarios en dicha formación. La educación para la responsabilidad del profesional es medular y propia de la formación a nivel de estudios de facultad. Ello supone que el egresado conozca, domine e interiorice como propios los más altos estándares de conducta que caracterizan, y que la sociedad exige y que la facultad pregona, de su ejercicio profesional. Cada profesión tiene exigencias éticas propias. Como se ha indicado, el ejercicio de la abogacía se fundamenta en valores que adquieren una concreción propia y distinta de la de otras profesiones. Valores como la libertad, la amistad, el principio de veracidad y el valor de la palabra tienen alcances y concreciones específicas para el profesional del Derecho.

Desde esa perspectiva, la principal responsabilidad de una facultad es la de formar un profesional en Derecho. Esto supone que debe educar no solo el «saber» (conocimientos) y el «saber hacer» (destrezas y habilidades interpersonales), sino también y fundamentalmente el «ser» (ámbito de los valores) del futuro abogado. No basta con el aprendizaje de la técnica del Derecho, esto es, el aprendizaje de conocimientos y la adquisición de destrezas que permitirían a una persona desempeñarse como un «buen abogado», sino que debe garantizar que el egresado ejerza el Derecho sobre la base de principios y del respeto de valores propios de la profesión. El mero hecho de aplicar el Derecho no hace a un abogado en toda la dimensión del término. Por eso, los valores, traducidos en la profesión en la responsabilidad profesional, son prioritarios. Si se forman abogados sin responsabilidad profesional se están creando técnicos que conocen un oficio pero no profesionales del Derecho. ${ }^{25}$

En ese marco, como se ha explicado, el profesional del Derecho debe representar muchos valores que tienen connotaciones particulares en la práctica de la profesión legal. No se trata ya de valores abstractos, sino de valores que se concretan en deberes específicos y exigen el desarrollo de medidas concretas, enfocadas en las particularidades del ejercicio de la profesión legal.

Desde la perspectiva de la construcción de la personalidad moral, en la educación de valores deben promoverse los siguientes rubros que analizamos a continuación: (a) a nivel conceptual y de conocimiento; (b) desarrollo de destrezas para poder resolver dilemas éticos; (c) espacios de reflexión en torno a uno mismo; y (d) creación y promoción de experiencias morales reales y simuladas.

25 Savater señala que «Los oficios y los instrumentos responden a unas normas de utilidad bastante claras, establecidas desdefuera[...]No sepide otracosa".SAVATER,Fernando. ÉticaparaAmador.Barcelona: Ariel, 2004, p. 11. Desde nuestro punto de vista, esto supone que el mero cumplidor de un oficio no requiera otra cosa que ser útilen la aplicación de una técnica, sin importar los valores o principios que rigen suactividad. Una profesión, por el contrario, tiene un sentido y cumple un rol en la sociedad por lo que las reglas éticas deben ser prioritarias. 


\section{a. Conocimientos}

En cuanto a los conocimientos para la formación en valores, se sostiene que «[...] los conceptos tienen que figurar en la enseñanza de valores». $\mathrm{Y}$ es que, en efecto, «tiene que haber un contenido conceptual para la adquisición de valores [...]. Si yo acepto la veracidad como una meta personal, es central tener presente qué significa la veracidad y qué supone dejar la falsedad en mi vida [...]. No puedo comprometerme con ningún objetivo si no lo conozco lo suficiente». ${ }^{26} \mathrm{El}$ alumno debe adquirir conocimientos sobre los valores de manera que a nivel conceptual tenga claro el alcance y contenido de cada uno. Por ejemplo, debe tener clara la diferencia entre no mentir y decir la verdad, toda vez que decir la verdad es mucho más que solo no decir mentiras, pues supone no ocultar una verdad que debe ser expresada.

Lo que importa en este nivel no es solo el conocimiento en sí mismo, sino también y centralmente «la relación de los estudiantes con lo que aprenden». ${ }^{27}$ Por ello, el nivel conceptual o teórico supone también una reflexión respecto de cómo dichos conocimientos se aplican en la vida del propio estudiante y qué opinión tiene este del valor en cuestión.

\section{b. Destrezas}

En cuanto a las destrezas para resolver dilemas éticos, partimos de nuestra experiencia en el dictado del Curso de Ética y Responsabilidad en la Facultad de Derecho de la PUCP y de las recomendaciones de Schmidt ${ }^{28}$ para señalar que los alumnos deben conocer cómo actuar y qué herramientas emplear al enfrentar un dilema ético. Así, consideramos que ante un dilema el estudiante debe estar en capacidad de poder: (i) realizar la detección temprana, que consiste en identificar la sensación que le produce la necesidad de adoptar una decisión en un tema conflictivo; (ii) identificar el conflicto al que se enfrenta, esto es, cuáles son los valores en juego —ello supone un proceso de introspección, así como la necesidad de que los alumnos cuenten con herramientas para evaluar sus propios condicionamientos y las causas de sus pensamientos-; (iii) visualizar los posibles escenarios y establecer pros y contras respecto de cada uno; y (iv) actuar.

\section{c. Espacio de reflexión en torno a uno mismo}

Además de promover el aprendizaje y la reflexión en torno a conocimientos y habilidades, es necesario brindar espacios de reflexión dirigidos a que el alumno pueda pensar respecto de sí mismo, esto es, espacios que ayuden al alumno a alumbrar su interior y poder conocerse mejor en el ámbito de los valores. 
Esta idea parte de entender que la persona humana, para enfrentar la libertad, para tomar decisiones en su vida y para saber cómo actuar frente a situaciones complicadas — como podrían ser los dilemas-, debe conocerse; es decir, saber quién es, en qué cree, qué le importa, cuáles son sus motivaciones, sus puntos débiles, sus temores y sus paradigmas de conceptos como libertad, justicia o autoridad, entre otros. Sobre el particular, Shopenhauer ${ }^{29}$ define al ser humano como un faro en tanto está acostumbrado a alumbrar hacia afuera cuando dentro todo es oscuridad. Pues bien, y como reconoce el autor mencionado, para que las personas alumbren hacia afuera con coherencia y valores es necesario que la luz se enfoque también en el interior. Por ello se requiere que existan espacios de reflexión destinados a lograr ese objetivo.

\section{d. Experiencias}

Hasta este punto hemos visto que la formación moral debe trabajarse a nivel de reflexión conceptual y a nivel de destrezas. Sin embargo, los estudiantes llegan a la universidad, principalmente, con un conjunto de experiencias vividas que en gran medida han formado los valores con los que ingresan y que han sido denominadas como la «cultura experiencial del estudiante»; esto es: «[...] la peculiar configuración de significados y comportamientos que los alumnos y alumnas de forma particular han elaborado, inducidos por su contexto, en su vida previa y paralela a la escuela, mediante los intercambios espontáneos con el medio familiar y social que ha rodeado su existencia $[\ldots] » .^{30}$

Por ello, los educadores no solo debemos proveer reflexión en torno al conocimiento y práctica, sino que también debemos brindar espacios en los que dicha cultura experiencial pueda ser contrastada con nuevas experiencias, de modo que exista la posibilidad de una reevaluación y complementariedad. Ello más aún cuando las universidades son «[...] precisamente esos lugares en los que muy valiosas actividades de muy distinta índole pueden promoverse para captar el corazón y las mentes de los estudiantes». ${ }^{31}$

Lo dicho nos lleva, entonces, a la principal propuesta formulada por autores como Schmidt ${ }^{32}$ y Puig dentro de su concepción de la educación de valores como construcción de la personalidad moral: la creación y promoción de experiencias morales.

Las experiencias morales son «[...] el ámbito donde se viven las experiencias que permiten a cada sujeto la definición de los problemas sociomorales», ${ }^{33}$ los mismos que son definidos como aquellos «conflictos

29 Schopenhauer, Arthur. Sobre la libertad. México D.F.: Fondo de Cultura Económica, 2000.

30 Pérez Gómez, Ángel. Op. cit., p. 199.

31 Duncan, Diane y Meter Silcock. Op. cit., p. 249.

32 Schmidtafirma,porejemplo,que «Cadapersonadesarrollasushábitosysuactitudmoralfundamentaldentro del contexto de sus relaciones con los demás". De allípodemos concluir la necesidad de trabajar a nivel de laexperiencia realen tanto estatiene lugar através de relaciones entre personas. SCHMIDT, Eduardo. Op. cit., p. 90.

33 PuIg R., Josep Maria. Op. cit., p. 161. 
morales que plantea la realidad». ${ }^{34}$ Estamos hablando, entonces, de espacios donde los alumnos viven determinadas situaciones que los hacen entrar en conflicto respecto de sus valores y de cómo resolver problemas concretos.

Sobre esa base, el autor menciona que existen experiencias morales simuladas o reales. Así, «[...] mientras una asamblea escolar suele plantear problemas reales tales como las peleas entre compañeros o las formas de organizar una fiesta, en otros momentos se discuten dilemas o se hacen otros ejercicios que plantean a los alumnos problemas que no viven directamente». ${ }^{35}$

Un ejemplo de experiencia moral real puede ser el planteado por Schmidt en los siguientes términos:

[un joven economista] consigue un trabajo relacionado con la elaboración de índices del costo de vida. Después de un estudio serio, descubre que el alza real en el último mes ha sido del 10\%. Al presentar esa información a su jefe, éste le contesta que debe haber algún error, porque el gobierno está seguro de que el costo de vida no podría haber subido tanto. El joven economista rehace sus cálculos y obtiene el mismo resultado. Al presentar sus conclusiones por segunda vez, su jefe le sonríe, y le pregunta si está contento en su trabajo. Su respuesta es afirmativa. Luego, el jefe le dice que si no desea sumarse a los miles de personas sin trabajo, debe rehacer su estudio para comprobar que la tasa de inflación no ha pasado del $2 \%{ }^{36}$

Esta experiencia real generaría cuestionamientos en la persona y le obligaría a plantearse cuáles son sus valores. Claramente, para el caso de la educación, este tipo de experiencias podrían promoverse de modo simulado, esto es, planteando casos hipotéticos a los alumnos o generando juegos de roles.

A su vez, en el ámbito de la educación legal, podríamos señalar que una experiencia moral real es el trabajo en una clínica jurídica. Sea que se trate del asesoramiento a una microempresa, a una comunidad campesina o a un joven que se desenvuelve al margen de la ley o a una microempresaria, podríamos encontrar el trabajo respecto a dos valores: (i) la justicia y libertad, en tanto se plantea el problema moral de cómo uno mismo se vincula o puede vincularse profesionalmente con dicha realidad, y si las normas son o no justas en dichos contextos; y (ii) respeto al otro, en tanto estamos en contextos donde el alumno debe tratar directamente con personas que piensan distinto y que tienen diferentes costumbres. 
Una experiencia moral simulada también podría ser la participación en la Contienda de Estudiantes Abogados al Banquillo, ${ }^{37}$ que tiene lugar en la Facultad de Derecho de la PUCP cada semestre, ya que en ella los alumnos deben desempeñar roles de abogados — defensores y acusadores- y jueces que deben resolver problemas éticos que se le presentan al abogado en el ejercicio profesional. En dichos casos, los alumnos se ven en la necesidad de plantearse qué es lo justo en el caso, qué sanción imponer, por qué imponerla, entre otros. En la audiencia pública final se presentan las acusaciones, defensas y resolución de primera instancia frente a un tribunal integrado por los connotados abogados y autoridades.

La educación en valores requiere que se le brinden al alumno oportunidades y espacios que le permitan experiencias de diversa índole que se confronten con sus experiencias previas, ello por dos razones adicionales. En primer lugar, el compromiso con determinados valores responde no solo a una reflexión racional, sino en gran medida también emocional, lo que se consigue promoviendo la vivencia de experiencias. En segundo lugar, presentar estas experiencias tiene un fuerte poder de cambio, puesto que de no ser ofrecidas o incluso obligadas, muchas personas no las tendrán nunca y, por ende, perderían la oportunidad de vincularse con el valor determinado. Esta idea queda bien clarificada con el siguiente ejemplo: «si yo encuentro de repente, después de trabajar en una tarea que puedo detenerme y elegir seguir o no seguir, yo podría evaluar que me ha dado la tarea en un modo que no hubiera sido posible antes de comenzar; y podré ver virtudes en ella que antes de comenzar no identifiqué».38

Evidentemente, como en el caso de la teoría y las destrezas, el trabajo de experiencias supone también que el profesor promueva la reflexión expresa respecto a los valores que se experimentan, de modo que dicho debate complemente debidamente la experiencia y signifique que los alumnos realmente se cuestionen sobre las situaciones vividas en ella.

37 «AbogadosalBanquillo» es una contiendadedestacados estudiantes de Derecho demitad decarreraen la quese debaten temas referidos a laética y responsabilidad profesional del abogado. Es unaactividad extra curricular, sincreditajenievaluación, en laquelosestudiantes participandemaneravoluntariadestinando sus vacaciones a la investigación y sustentación de las posiciones que les toca representar. Para ello, se formangruposqueasumendiversosrolesenlasolucióndecasosconcretosderesponsabilidadprofesional: rol de defensor, de acusadores y la comisión que resuelve el caso. Todos los grupos simulan el proceso deresolución delcaso,conociendoloshechosyformulandopreguntas,elaborandoescritosdedenunciay contestacióny, finalmente,exponiendosusalegatosanteuntribunaldehonorconformadopordestacados profesoresyabogados, aquienes lescorrespondedecidircuálessonlosgruposganadoresdelacontienda. Esta última etapa tiene lugar en el auditorio de Derecho y se lleva a cabo ante unas $\mathbf{3 0 0}$ personas que conformanelpúblico-elingresoaleventoeslibreparaestudiantes, profesoresypersonas interesadas-. Laactivaparticipacióndelosestudiantes,tantocomomiembrosdelosgruposdetrabajocomoasistentesala audienciapúblicafinal, dacuentadelespacioquellenaestaactividadenlapromocióndelaresponsabilidad profesional del abogado en la PUCP. El concepto y la metodología de Abogados al Banquillo fue diseñado por Beatriz Boza.

38 Duncan, Diane y Meter Silcock. Op. cit., p. 250. 


\section{Métodos para la formación en valores en Derecho}

En el ámbito de las facultades de Derecho, la formación en valores puede viabilizarse a través de los siguientes métodos a ser tomados en cuenta en un plan de estudios: (i) cursos, (ii) actividades, (iii) cultura organizacional y (iv) liderazgo y ejemplo. Veamos brevemente en qué consiste cada uno de ellos.

\section{a. Cursos}

El trabajo en el aula es particularmente relevante en todo lo referido al conocimiento de los estándares de responsabilidad profesional y a las destrezas y la manera de resolver problemas éticos concretos que se le presentan al abogado de docencia en tanto explica y expone el tipo de conducta esperada de él en su quehacer diario en el Perú.

Hemos identificado dos maneras en que las facultades de Derecho del medio abordan la formación en los valores de la responsabilidad profesional del abogado. ${ }^{39}$ En un caso es a través de un curso denominado Deontología Forense y, en el otro, de Ética y Responsabilidad Profesional.

1) Deontología Forense. Usualmente se ha abordado la formación del estudiante de Derecho en los valores de la responsabilidad profesional del abogado a través de cursos de Deontología Forense o de Ética y Valores. El enfoque tradicional de formación moral del estudiante de Derecho va de la mano con el enfoque disciplinario que inspira el Código de Ética vigente ${ }^{40}$ y la colegiatura obligatoria en nuestro medio, girando en torno a principios generales y enunciados aspiracionales, exigibles por lo general a nivel de la conciencia particular del propio individuo. Ejemplo de ello son el principio de buena fe o el de conducta honrosa, que se buscan inculcar únicamente a través de la reflexión teórica y la discusión de textos en el plano abstracto.

2) Responsabilidad Profesional. El enfoque tradicional contrasta con lo establecido en regímenes enfocados a establecer reglas concretas, objetivas y, por ende, exigibles a los abogados en materia de responsabilidad profesional. Así, en vez de limitarse a exhortar e invocar principios generales de buena fe, dignidad, honorabilidad y decoro profesional, la formación centrada en la responsabilidad profesional aporta cánones y pautas concretas que orientan la conducta del estudiante y del abogado. Los contenidos conceptuales y prácticos que se busca brindar al alumno van desde la

39 Una primera revisión de los planes de estudio de facultades de Derecho representativas del mercado (Universidad de Lima, Universidad de Ciencias Aplicadas, Universidad San Martín y Universidad Mayor de San Marcos)permiteconcluirquelosvaloresseabordanenelámbitodelcursodeDeontologíaForense. Esta revisión no abarcó, sin embargo, los sílabos ni materiales deenseñanza afin de determinar qué rubros son trabajados.

40 Nos referimos al Código de Ética de los Colegios de Abogados del Perú, aprobado por la Junta Nacional de Decanos de los Colegios de Abogados del Perú, en su sesión del 26 de abril de 1997. 
determinación de su relación con el cliente, pasando por temas de secreto profesional, conflicto de intereses, custodia de bienes del cliente y causales de renuncia obligatoria, hasta la fijación de honorarios, relación con la contraparte y responsabilidad por el centro de trabajo. Todo lo anterior suele estar plasmado en un Código de Responsabilidad del Profesional en Derecho, el que por su orientación práctica y general tiene un efecto abogado en rubros específicos de su relación con el cliente, la autoridad, la contraparte y la sociedad.

Aun cuando en la formación del estudiante se requiere un curso que aborde el contenido de la responsabilidad profesional, más allá de ese curso, a lo que debe propenderse es a lograr contenidos transversales a lo largo de la carrera, pues es ello lo que genera en el estudiante la noción de la importancia de la responsabilidad profesional y la comprensión de los valores desde distintos ángulos. Un modo muy eficaz de introducir cambios en los cursos es el método de infusión (trabajo transversal). Como advierte Frisancho, la formación de la identidad moral no necesariamente requiere de un curso. ${ }^{41} \mathrm{~A}$ modo de ejemplo, en diversas universidades de Estados Unidos para abordar la responsabilidad profesional se ha adoptado un método trasversal ${ }^{142}$ que supone incentivar a diversos profesores para que en sus cursos puedan incluir reflexiones y trabajo práctico respecto a temas de ética. De ese modo se busca que la ética sea trabajada en diversos cursos. Así, en la medida de lo posible, se debe proponer que los profesores planteen antes de iniciar sus cursos la pregunta: iqué reglas éticas debemos seguir en este curso? Ello con la finalidad de que, a través de la autorregulación, los alumnos adviertan la importancia de las reglas éticas en su experiencia como estudiantes y se acostumbren a reflexionar sobre el particular. Nótese que este método sirve también para trabajar en los distintos niveles de la formación en valores, como el teórico, de destrezas, experiencias morales y currícula oculta. Utilizando el método de infusión, debería lograrse, por ejemplo, que en la mayor cantidad de cursos los profesores reflexionen sobre si las diferentes leyes y normas que se estudian son o no justas.

Nótese también que la creación de cursos da cuenta del interés de la facultad en una materia determinada, lo que influye a nivel de currícula oculta. Así, por ejemplo, si se crean dos cursos electivos sobre temas de responsabilidad profesional y un curso obligatorio sobre la experiencia práctica del alumno en temas de responsabilidad profesional en el Perú, la Facultad está dando cuenta de su interés por la ética y la justicia, respectivamente. Esto influye en la percepción que los alumnos tienen de los temas en cuestión.

41 Frisancho, Susana. La identidad moral: elemento fundamental para la enseñanza en derechos humanos. Lima: IDEHPUCP, 2007, p. 7.

42 Véase, comoejemplo, MenKel-Meadow, Carriey RichardSAnder. «The "Infusion" MethodatUCLA:Teaching Ethics Pervasively». Law and Contemporary Problems, vol. 8, nº 3/4, pp. 129-138. 
En cuanto a la currícula oculta, el contar con profesores preocupados por trabajar dentro de sus cursos temas relacionados con diversos valores, da cuenta de su interés en cada uno de ellos, lo que definitivamente también influye en la percepción de los alumnos.

\section{b. Actividades}

En muchos casos es necesario introducir y ofrecer diversas actividades en las que los alumnos puedan reflexionar y desenvolverse con familiaridad en temas referidos a la ética y valores en el ejercicio profesional. El beneficio del trabajo a través de actividades radica principalmente en la flexibilidad que se tiene para lograr los objetivos. Esta flexibilidad - tanto en términos de su formato, duración y contenido- abre la posibilidad a una serie de actividades, algunas obligatorias y otras electivas, orientadas a facilitar la inmersión del estudiante en la cultura que se desea cultivar en una facultad de Derecho.

El aprendizaje por la experiencia en actividades concretas es particularmente relevante en materia del Derecho. Ello porque en la realidad del ejercicio profesional se han asumido ciertas prácticas contrarias a la ética y al Estado constitucional de derecho. Los alumnos, al ingresar en ese mundo, terminan adoptando esas conductas que, por lo demás, son usuales en nuestra sociedad en general. Así, se deben presentar experiencias que contrasten esos paradigmas y que les permitan formar su propia opinión, conocerse, de modo que puedan estar preparados para enfrentarlos.

Un ejemplo concreto de actividades que promueven la reflexión individual es el de «Instituciones en nuestras mentes». Se trata de una experiencia en Estados Unidos y Europa que busca que los estudiantes reflexionen sobre sus propias categorías mentales, muchas veces inconscientes, con las que se aproximan a valores determinados. Así, se trabaja, con asesoramiento de expertos en relaciones grupales, cuál es la concepción que tienen los asistentes sobre justicia, autoridad, libertad, entre otros. La idea es descubrir las mecánicas inconscientes que tienen los alumnos y que no son descubiertas sino a través de la reflexión basada en la experiencia que proporcionan mecanismos como este.

\section{c. Cultura organizacional}

Toda facultad de Derecho es la «antesala» del trabajo profesional del abogado, toda vez que la cultura, prácticas y valores, incluso ocultos, de la facultad determinan en gran medida el «ADN» del egresado. La cultura y la gestión organizacional, así como la interrelación en general entre profesores, autoridades, personal administrativo y estudiantes, gestan la currícula oculta. Lo que se busca es que la institución cumpla con ciertos estándares — por lo menos mínimos- en torno a los diferentes

FORMACIÓN EN VALORES: ¿RESPONSABILIDAD DE LA FACULTAD DE DERECHO? 
valores. De ese modo, por ejemplo, una facultad debe ser muy rigurosa con el cumplimiento de plazos en los trámites administrativos, debe tolerar y promover las críticas, e incitar el debate a través de eventos y talleres, entre otros.

\section{d. Liderazgo y ejemplo de compromiso con la justicia}

Los estudiantes requieren interactuar con personas cuya actuación profesional les sirva de ejemplo. Ello supone ser consciente y cuidar que la plana docente de la facultad interiorice esa función. En tal sentido, existen ciertos estándares mínimos que deben ser comunes a todos los catedráticos de la facultad y que deberían ser exigibles sin excepción. Por ejemplo, ninguno de los profesores debemos sugerir la posibilidad de utilizar medios ilegales para ganar un caso u obtener un trabajo.

Los profesores, particularmente aquellos que ejercen la profesión legal, deberíamos tener un conocimiento actualizado de las reglas de la responsabilidad profesional, de modo que, mediante la transversalidad, seamos ejemplo para los alumnos. En Estados Unidos, por citar un caso, «[...] la profesión legal ha ajustado y readecuado sus exigencias. Es más, un requisito indispensable de quienes practican el ejercicio de las leyes norteamericanas es el de completar cursos anuales de educación continua (Continuing Legal Education)». Estos cursos, en lo que nos ocupa, tienen «[...] por lo menos cuatro créditos al año dedicados a temas de ética». ${ }^{43}$

Por otro lado, es congruente con valores como el respeto al otro o la responsabilidad social permitir e incluso promover que existan profesores con diferentes puntos de vista, ya que ello promueve el debate y la currícula oculta gana en cuanto a diversidad. En esa lógica, por ejemplo, es importante promover la diversificación de la plana docente a fin de que existan diversos modelos de abogados en la cultura de la Facultad de Derecho.

\section{e. Monitoreo y evaluación permanente}

Finalmente, la evaluación en un proceso de aprendizaje sirve para identificar el grado de avance, las áreas de aprendizaje y las oportunidades de mejora y reforzamiento. En este caso la evaluación es primordial, pero, a diferencia de cualquier otro proceso de aprendizaje, no son a los alumnos a quienes se tiene que evaluar, sino es a la propia Facultad y, en particular, el cuerpo docente y administrativo, quienes debemos ser evaluados. Para ello se deben desarrollar y aplicar encuestas de percepción a los estudiantes respecto de los temas aquí planteados, incluyendo especialmente su percepción sobre el papel de la ética y los valores en el ejercicio profesional. Ello permitirá tener una línea de base sobre la 
cual se puedan evaluar cada dos años los avances en la formación en valores.

\section{CONCLUSIÓN}

La educación en valores se centra en aquellos deberes obligatorios para todo profesional del Derecho. No se trata de estándares que uno puede decidir no cumplir, sino de obligaciones que debe asumir todo abogado por el hecho de ser abogado. Sin embargo, la educación moral tiene también otro nivel que, aunque muy vinculado, busca promover la libertad de los alumnos al elegir qué tipo de ejercicio profesional desean llevar a cabo. Este es un plano donde se promueve, a través de diversas medidas, que el alumno elija libremente un proyecto de vida determinado desde el Derecho. Aunque muchas de las consideraciones y medidas que hemos descrito coadyuvan a cumplir con esta finalidad, lo cierto es que nuestro trabajo se ha centrado en cómo una facultad de Derecho debe asumir su responsabilidad prioritaria en la educación moral: el que sus egresados tengan altos estándares de responsabilidad profesional, estándares obligatorios para todo profesional del Derecho.

La idea es clara: educar en valores no es tener un discurso sobre ellos o declarar que son importantes, es necesario trabajar en los niveles antes mencionados y a través de acciones concretas.

\section{BIBLIOGRAFÍA COMPLEMENTARIA}

\section{Sobre educación legal en Perú}

Del MAstro, Fernando. «Ética, abogados y educación legal: una aproximación desde la libertad de conciencia». En Compendio de ensayos sobre ética y responsabilidad profesional. Lima: Ius Et Veritas, 2008, pp. 465-507.

FreYre CASTILlo, Mario. La reforma de la enseñanza jurídica en debate: métodos y contenidos en la Facultad de Derecho de la Pontificia Universidad Católica del Perú. Lima: Foro Académico, 2005.

Gonzales Mantilla, Gorki. La enseñanza del Derecho o los molinos de viento: cambios, resistencias y continuidades. Lima: Palestra, 2008.

PÁsARA, Luis. La enseñanza del Derecho en el Perú: su impacto sobre la administración de Justicia. Lima: MINJUS, 2004.

RuBio, Marcial. Ideas sobre qué es aprender (y enseñar) Derecho en un pregrado. Lima: Fondo Editorial PUCP, 2002.

Zusman, Shoschana. «Aprendiendo a aprender». En Homenaje a Jorge Avendaño. Lima: Fondo Editorial PUCP, 2004. 


\section{Sobre educación moral}

BoIsvert, Jacques. La formación del pensamiento crítico. México D.F.: Fondo de Cultura Económica, 2004.

Delval, Juan. Los fines de la educación. Madrid: Editora Siglo XXI, 1991.

PiAgGET, Jean. El criterio moral en el niño. Barcelona: Martínez Roca, 1984.

\section{Sobre responsabilidad profesional del abogado}

BozA, Beatriz. «Inter estudios, escándalo y crisis: Themis y la responsabilidad profesional del abogado en el Perú». Revista Themis, no 50, 2004, pp. 69-72.

— «Publicidad en la abogacía: necesidad de repensar los estándares éticos de la profesión». Advocatus, no 13, 2006, pp. 373-383.

— «La educación legal: necesidad de una reforma para la calidad». Perú Económico, abril de 2007.

— «Tomando al toro por las astas». Enfoque, nº 60, abril de 2007.

— «La eficacia de la responsabilidad profesional del abogado y el liderazgo de Ius et Veritas». Revista Ius et Veritas, no 33, 2007, pp. 411-417.

— «19 ensayos de interpretación de la realidad del abogado peruano». En Compendio de ensayos. Ética y responsabilidad profesional del abogado. Lima: Ius et Veritas, 2008, pp. 9-14.

Boza, Beatriz y Christian Chocano. «Exposición de motivos del Proyecto de Código de Ética». Revista Themis, 2008. 